\title{
Pengaruh Pelatihan Tanggung Jawab Sosial Pada Mahasiswa Senior Resident Di Asrama X
}

\author{
Nurul Aisyah* ${ }^{1}$, Yogi Pambudi ${ }^{2}$, Ratna Djuwita ${ }^{* 3}$ \\ ${ }^{1,2,3}$ Fakultas Psikologi, Universitas Indonesia \\ E-mail : *1ํㅡeah0111@gmail.com, ${ }^{2}$ yogipambudi27@gmail.com, ${ }^{3}{ }^{3}$ juwita@ui.ac.id
}

\begin{abstract}
Abstrak
Tanggung jawab sosial (social responsibility) merupakan salah satu faktor yang menyebabkan seseorang atau sekelompok orang merasa menjadi bagian dari suatu tempat atau posisi tertentu. Penelitian menunjukkan bahwa ketidaktahuan atas peran yang diemban oleh seseorang atau sekolompok orang menyebabkan mereka tidak menyadari tanggung jawab sosial terhadap lingkungan sekitar. Oleh karena itu metode pelatihan dipilih untuk menyadarkan mahasiswa Senior Resident mengenai tanggung jawab sosial dan peran yang diemban. Tujuan penelitian ini adalah untuk mengetahui pengaruh pelatihan sosial responsibility dalam meningkatkan tanggung jawab sosial mahasiswa Senior Resident. Penelitian ini menggunakan rancangan small sampel experiment selama satu hari. Partisipan penelitian ini adalah 13 mahasiswa Senior Resident di asrama mahasiswa universitas $X$ dan 106 partisipan mahasiswa asrama tahun pertama. Data yang dikumpulkan adalah data primer. Hasil penelitian ini memperlihatkan adanya peningkatan pada Social Responsibility dan Place Attactment pada partisipan walaupun tidak signifikan, namun seiring berjalannya waktu terus meningkat dalam tiga kali pengukuran. Implikais pelatihan ini membutuhkan keberlanjutan dalam penerapan berbagai action plan social resposibiliy untuk dapat memperoleh hasil yang signifikan.
\end{abstract}

Kata Kunci-Asrama, Mahasiswa, Tanggung jawab sosial, Place Attachment.

\begin{abstract}
Social responsibility is one factor that causes a person or group of people to identify him/herself as a part of palce and community. Research shows that Research shows that being unaware of their social responsibility is the cause of people's ignorance towards their social surrounding. The purpose of this study was to determine the effect of social responsibility training in increasing social responsibility of a group of Senior Resident students in the dormitory of university " $X$ ". The study was differentiate in four stages: Base line (pre-test), social responsibility training, action plan and posttest. This study involved 13 Senior Residents and 106 first year dormitory residents. Quantitative (questionnaires) and qualitative data (interview) was used to measure the training effect.The results of this study indicate an increase in Social Responsibility and Place Attachment in participants, although it is not significant, but data shows an increase of social responsibility in three times measurement. The implication of this study is the importance of sustainability of training and action plan to obtain significant results.
\end{abstract}

Keywords—Dormitory, Social Responsibility, Place Attachment, Students. 


\section{PENDAHULUAN}

Penerimaan mahasiswa baru adalah kegiatan rutin yang dilaksanakan universitas, termasuk pada Universitas X. Kegiatan ini dilakukan untuk menemukan mahasiswa unggul yang berasal dari berbagai daerah. Berbagai fasilitas disediakan untuk mendukung proses adaptasi mahasiswa baru, diantaranya penyediaan asrama mahasiswa. Asrama X merupakan fasilitas yang ditawarkan bagi mahasiswa baru Universitas $X$ untuk tinggal selama menjalankan proses perkuliahan. Asrama X menawarkan biaya sewa yang lebih terjangkau dengan berbagai fasilitas seperti kantin, transportasi umum kampus, serta wi-fi yang bisa diakses 24 jam.

Asrama X memiliki visi menjadi tempat tinggal mahasiswa terbaik di Asia Tenggara tahun 2030. Untuk mencapai visi ini, Pengelola Asrama dengan optimal menyediakan pelayanan bagi para penghuninya. Diharapkan dengan adanya fasilitas dan optimalisasi pelayanan, penghuni Asrama dapat merasakan kenyamanan untuk beraktivitas di asrama. Selain itu,untul lebih mengoptimalkan pencapaian tujuan tersebut, pihak asrama membentuk Senior Resident yang berfunsi sebagai model bagi penghuni baru di Asrama X.

Senior Resident merupakan mahasiswa tahun kedua atau ketiga yang diseleksi untuk dapat membantu Asrama dalam mengingatkan penghuni asrama menjalankan peraturan yang berlaku di asrama (ER, wawancara pribadi, 9 Agustus 2019). Senior Resident biasanya terdapat pada setiap lantai di Gedung asrama. Secara umum, Senior Resident memiliki hak izin tinggal di Asrama selama menjabat. Adapun kewajiban Senior Resident meliputi berkewajiban melaksanakan kegiatan yang sesuai dengan visi dan misi asrama; menjadi pelaksana tugas sementara penanggung jawab gedung saat pengelola asrama tidak ada; menjadi pengawas pelaksana tugas bagi lembaha dan komunitas semi otonom yang ada di asrama X. Oleh karena itu, Mereka diharapkan dapat membantu penyesuaian diri mahasiswa baru dengan lebih peka terhadap kondisi penghuni asrama dan juga menghangatkan interaksi penghuni asrama dengan mengadakan kegiatan rutin (ER, wawancara pribadi, 9 Agustus 2019). Mereka merupakan pihak yang berinteraksi langsung dengan mahasiswa baru. Fungsi Senior Resident haruslah dimaksimalkan agar dapat menjalankan perannya dengan optimal, khususnya membantu mahasiswa baru beradaptasi dan dapat membuat kegiatan yang dapat meningkatkan interaksi dan kehangatan dalam asrama.

Dari wawancara dengan penghuni asrama diketahui bahwa sudah ada beberapa aktivitas yang diadakan oleh Senior Resident dalam meningkatkan interaksi antara warga asrama dan meningkatkan kepedulian lingkunga, namun banyak warga asrama yang kurang tertarik atau yang hadir. Menurut mahasiswa yang diwawancara, warga asrama yang hadir dalam kegiatan hanya warga 'yang itu-itu saja'(DI, wawancara ribadi, 18 Agustus 2019). Beberapa acara yang diadakan dianggap kurang menarik minat mahasiswa asrama. Acara yang diadakan untuk dapat meningkatkan interaksi mahasiswa baru menjadi tidak tercapai. Selain itu ada beberapa warga asrama yang enggan meminta bantuan Senior Resident dikarenakan tidak kenal baik dan 'takut merepotkan'. Ada beberapa warga asrama yang pemalu dan menutup diri sehingga enggan berinteraksi dan meminta bantuan pada Senior Resident walaupun mereka merasa membutuhkan bantuan. Selain itu, memang ada beberapa Senior Resident yang sibuk dengan kewajibannya sebagai mahasiswa, sehingga tidak dapat membantu penghui asrama dengan optimal.

Hal ini menunjukkan bahwa ada permasalah di asrama $\mathrm{X}$ yang mengindikasikan asrama belum menjadi lingkungan primer bagi penghuninya. Menurut Bell, Greene, Fisher dan Baum (2011) lingkungan primer merupakan tempat dimana penguninya dapat meningkatkan kesempatan untuk bertemu dengan orang disekitarnya secara teratur, membangun hubungan personal dengan mereka dan berpartisipasi dalam berbagai aktivitas untuk mencapai tujuan bersama. Hal ini menyebabkan kurangnya tanggung jawab sosial bersama sehingga menjadikan peghuni tidak peduli lingkungan sosial maupun lingkungan fisik di sekitar asrama. Sehingga terlihat ruang bersama yang brserakan sampah dan penghuni asrama yang tidak 
saling kenal dengan tetangga asramanya. Hal ini bisa diatasi jika tanggung jawab sosial masing-masing peran di asrama dijalankan dengan optimal.

Tanggung jawab adalah keterlibatan individu dalam pekerjaan dan lingkungannya, seperti ada kesempatan, ada kesanggupan dan ada penguasaan diri sendiri dalam menyelesaikan pekerjaanya. Seseorang yang diberikan tanggung jawab dan wewenang oleh organisasi artinya mereka diberikan kesempatan dan dipercaya oleh organisasi untuk melakukan tugasnya sendiri (Secchi \& Bui, 2018). Dengan begitu didalam diri mereka akan muncul rasa tanggung jawab dan keinginan untuk menyelesaikan tugasnya dengan baik dan mencapai tujuan bersama.

Tanggung jawab sosial dinilai penting untuk dimiliki oleh setiap individu agar dapat bermanfaat bagi lingkungan sekitar. Tanggung jawab sosial ini dipengaruhi oleh keterikatan degan tempat (Vaske \& Kobrin, 2001), dimana semakin orang merasa memiliki keterikatan degan suatu empat maka semakin ia sadar dengan tanggung jawab sosialnya pada lingkungan tersebut. Saat pihak-pihak yang berperan dapat memahami, menginternalisasi dan melaksanakan tanggung jawab sosialnya maka akan meningkatkan kepuasan hidup orang sekitar yang tinggal berdampingan dengan mereka, meningkatkan keterikatan penghuni lain pada lingkungan tersebut dan dapat menjadikan penghuni lain memiliki rasa menjadi bagian dari tempat tersebut dalam hal ini asrama (Weijs-Perrée, Van den Berg, Arentze \& Kemperman, 2017). Sehingga hal ini dapat membantu asrama untuk mencapai tujuan bersama menjadi hunian terbaik di Asia Tenggara. Berdasarkan hal tersebut dinilai penting untuk melakukan intervensi dalam meningkatkan penyadaran dan pemahaman tanggung jawab sosial pada Senior Resident di asrama. Sehingga dapat berdampak pada penghuni asrama lain.

Tanggung jawab adalah keterlibatan individu dalam pekerjaan dan lingkungannya, seperti ada kesempatan, ada kesanggupan dan ada penguasaan diri sendiri dalam menyelesaikan pekerjaanya. Seseorang yang diberikan tanggung jawab dan wewenang oleh organisasi artinya mereka diberikan kesempatan dan dipercaya oleh organisasi untuk melakukan tugasnya sendiri (Secchi \& Bui, 2018). Menurut Schiller \& Bryan (2002) tanggung jawab adalah perilaku yang menetukan bagaimana bereaksi terhadap situasi sehari-hari, yang memerlukan beberapa jenis keputusan moral. Mudjiono (2012) merumuskan bahwa tanggung jawab merupakan sikap yang berkaitan dengan janji atau tuntutan terhadap hak, tugas, dan kewajiban sesuai denganaturan, nilai, norma, adat istiadat yang dianut oleh kelompok tertentu.

Burhanuddin (2000) menyatakan bahwa ada beberapa aspek dari tanggung jawab, yaitu kesadaran, kecintaan atau kesukaan, dan keberanian. Kesadaran dalam hal ini meliputi kesadaran akan etika, melakukan perencanaan dan melaksanakannya dengan fleksibel, serta sikap produktif untuk mengembangkan diri. Kecintaan atau kesukaan diartikan sebagai sikap empati dan bersahabat dalam hubungan interpersonal. Keberanian meliputi kemamuan bertindak independen dan mampu melihat perilaku dari segi konsekuensi atas dasar sistem nilai. Selain aspek dari tanggung jawab, ada beberapa ciri-ciri dari seseorang yang bertanggung jawab (Raphael \& Pearson, 1985; Fischer \& Ravizza, 2000), antara lain: Melakukan tugas rutin tanpa harus diberi tahu dan sadar atas tanggung jawab atas tugas yang diemban; Dapat menjelaskan maksud dan tujuan apa yang dilakukan; Tidak suka menyalahkan orag lain; Memiliki kemampuan dalam menentukan pilihannya yaitu orang yang memiliki kesadaran maka dapat menentukan tindakan dan keputusan yang diambil dalam situasi tertentu; Bisa membuat keputusan sendiri yang berbeda dengan keputusan kelompoknya; Menghormati dan menghargai aturan; Dapat berkonsentrasi pada tugas-tugas yang rumit; Perkataan sejalan dengan tindakan; serta mengakui kesalahan tanpa mengajukan alasan yang dibuat-buat.

Fischer \& Ravizza (2000) menyatakan bahwa tanggung jawab sosial dapat dipengaruhi oleh beberapa hal yaitu kurangnya kesadaran akan pentingnya melaksanakan hak dan kewajiban yang merupakan tanggung jawabnya. Selain itu tanggung jawab sosial juga dapat dipengaruhi dengan rasa percaya diri terhadap kemampuan yang dimiliki, dimana semakin percaya diri seseorang terhadap kemamuan yang dimiliki, maka semakin tinggi juga 
kesadarannya tentang tanggung jawab sosial yang diemban. Faktor lain yang dapat mempengaruhi adalah keberfungsian dari stakeholder terkait tanggung jawab yang diemban.

Tanggung jawab sosial erat kaitannya dengan place attachment (Heidari \& Nekooeimehr, 2013; Scanell \& Gifford, 2017; Junot, Pauet \& Fenouillet, 2018), residential satisfaction (Adriaanse, 2007; Scanell \& Gifford, 2017; Botti \& McGill, 2016; Shahyad, Besharat, Asadi, Alipour \& Miri, 2011), serta sense of belonging (Singh, 2018; Heidari \& Nekooeimehr, 2013). Place attachment adalah hubungan simbolis yang terbentuk pada seseorang yang secara kultural memberikan pengertian emosi kepada suatu ruang atau tempat yang menjadi basis seseorang atau sekellompok orang dalam memahami hubungannya degan lingkungan sekitarnya (Heidar \& Nekooeimehr, 2013; Scanell \& Gifford, 2017). Place attachment dan tanggung jawab sosial memiliki hubungan dimana ketika place attacment meningkat maka tanggung jawab sosial seseorang terhadap tugas tau kewajibannya pada tempat itu juga akan meningktat. Hal ini juga berlaku sebaliknya. Sehingga dapat dikatakan jika seseorang diberikan stimulasi untuk meningkatkan tanggung jawab sosialnya maka place attachment pada orang tersebut juga akan meningkat.

Aspek-aspek diatas juga tidak lepas dari kualitas hunian atau asrama. Kualitas tempat tinggal, dalam konteks ini asrama, dapat dilihat dari ruangan, masa kepemilikian, struktur dalam perawatan dan norma pertetanggaan. Kutty (1999) mengidentifikasi beberapa indikator lain untuk melihat kualitas dari tempat tinggal, yakni struktur yang adekuat, kualitas pertetanggaan (sosial) yang baik, keamanan lingkungan, fasilitas umum, dan terdapat akses untuk bekerja. Austin dkk (2002) dan Kaplan \& Kaplan (2003) menambahkan aspek yang paling utama untuk mengetahui kualitas dari tempat tinggal yaitu sistem pertetanggaannya, keamanan, serta kebersihan lingkungan. Morris dkk (1976) menyebutkan bahwa aspek tersebut dapat memudahkan enghuni untuk menyesuaikan diri.

Mowen (2008) membuat gambaran kepuasan penghuni sebagai rasio kualitas hunian yang ditempati dimana kebutuhan, keinginan, serta harapan penghuninya terpenuhi. Rasio ini memberikan pengertian bahwa kepuasan tinggal dapat terwujud apabila kualitas yang ditempati sesuai dengan kebutuhan dan harapan penghuninya, sehingga bisa memberikan dampak positif bagi peningkatan kualitas hidupnya. Dalam hal ini, kepuasan menetap di asama dapat diterjemahkan sebagai sebuah proses kognitif penghuni asrama pada asrama, mulai dari memperhatikan, merasakan, dan memproses informasi yang didapat atau dirasakan pada hunian tersebut, sehingga penghuni mampu memilai apakah sesuai dengan keinginan, kebutuhan dan harapannya. Termasuk didalamnya interaksi sesama enghuni dan Senior Resident. Keinginan, kebutuhan dan harapan tinggal yang dimaksud di dalamnya adalah hunian yang nyaman, sehat dan sesuai dengan fungsi asrama itu sendiri. Sehingga, kenyamanan tinggal merupakan produk dari rasa puas penghuni terhadap asrama yang ditempati.

Berdasarkan paparan diatas ditemukan permasalahan penghuni asrama $\mathrm{X}$ yang tidak saling kenal satu sama lain. Selain itu, penghuni juga kurang memperhatikan lingkungan fisik serta lingkungan sosial yang ada di asrama X. Senior Resident bertanggung jawab sebagai salah satu jaringan dukungan sosial penghuni asrama, tindakan atau perilaku dari Senior Resident sedikit banyak akan mempengaruhi kehidupan penghuni asrama lain di asrama. Oleh karena itu, pada penelitian ini dilakukan intervensi pelatihan tanggung jawab sosial bagi Senior Resident. Tujuan intervensi ini untuk mengoptimalkan tanggung jawab sosial pada Senior Resident yang diharapkan akan mempengaruhi perilakunya. 


\section{METODE PENELITIAN}

\subsection{Partisipan}

Partisipan dari penelitian ini adalah tiga belas dari 26 total Senior Resident (SR) asrama $\mathrm{X}$ untuk masa jabatan 2019. SR asrama $\mathrm{X}$ ini memiliki tanggung jawab untuk menjadi role model dari 1300 penghuni yang ada di Asrama X. Partisipan Senior Resident diukur sebanyak tiga kali yaitu pada sebelum pelatihan, setelah pelatihan dan setelah melaksanakan proyek aksi sosial. Selain, SR, peneliti juga mengambil partisipan penghuni asrama X sejumlah 106 partisipan yang diukur kepuasan hidup berdampingan dengan Senior Resident, place attachment (selama hidup di asrama) dan sense of belonging terhadap asrama sebelum dan setelah menerima program aksi sosial dari Senior Resident.

\subsection{Desain}

Jenis penelitian yang digunakan dalam penelitian ini adalah penelitian eksperimen yang merupakan penelitian sistematis untuk menguji hipotesis hubungan sebab-akibat. Desain yang digunakan dalam penelitian ini adalah desain Satu Kelompok Pretes Postes (One Group PretestPosttest) pada partisipan Senior Resident. Penelitian ini mengunakan data kuantitatif yang dudukung dengan data kualitatif.

\subsection{Prosedur}

Penelitian dilakukan dari tanggal 22 September 2019 sampai dengan 6 November 2019. Kegiatan rangkaian pelatihan, seperti pelatihan itu sendiri, pembimbingan program aksi sosial dan pelaksanaan aksi sosial dilakukan pada setiap akhir pekan selama rentang waktu penetian. Bentuk Diagram prosedur penelitian ditunjukkan sebagai berikut:

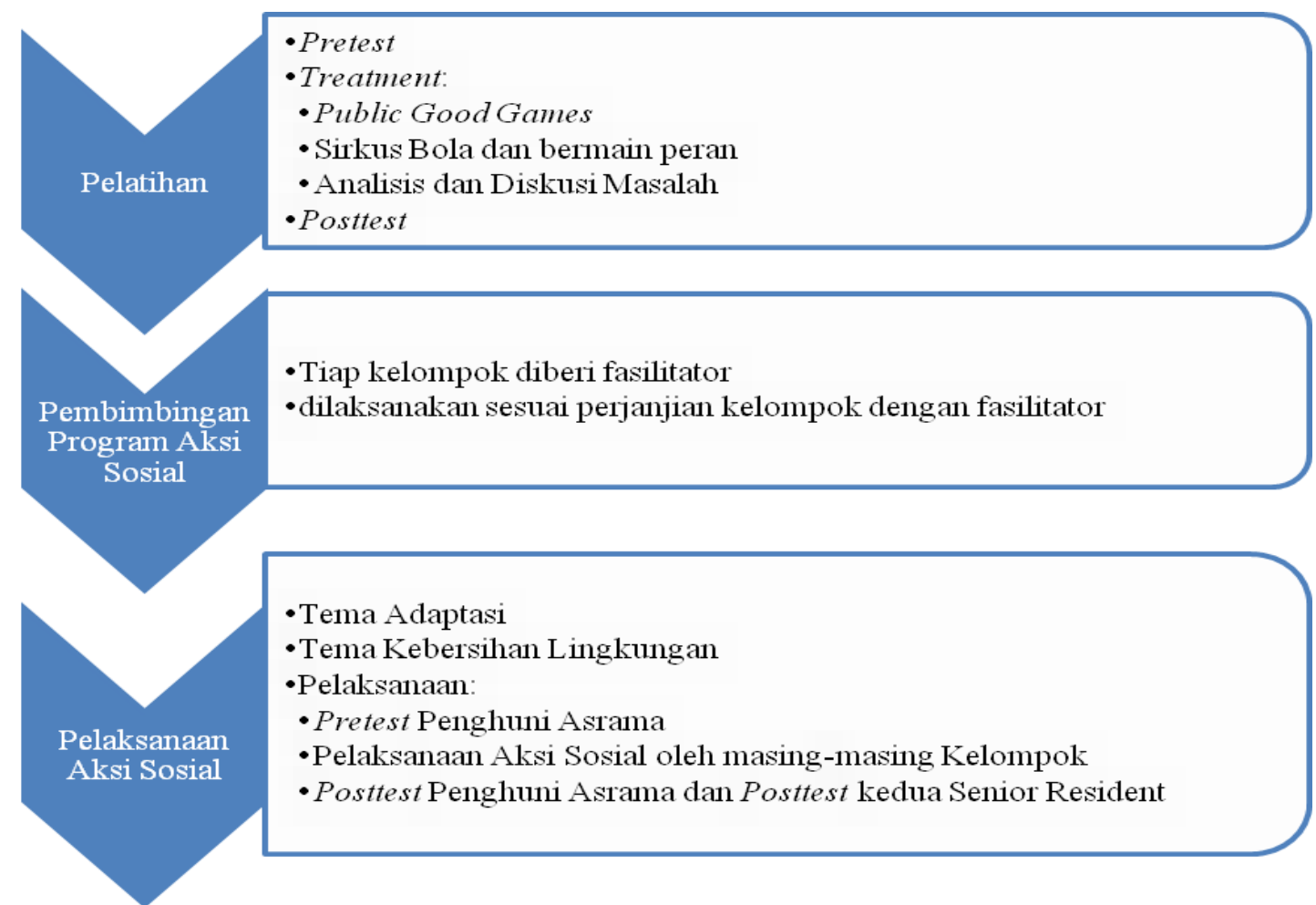

Gambar 1. Diagram Prosedur Penelitian Pelatihan Tanggung Jawab Sosial Senior Resident Asrama X 
Berdasarkan Gambar 1, sebelum perlakuan diberikan terlebih dahulu sampel diberi pretest dan di akhir pembelajaran sampel diberi posttest. Sebelum treatment diberikan, partisipan akan diberikan tes (pretest) untuk mengetahui aspek tanggung jawab sosial dan keterikatannya kepada asrama sebelum dilakukan treatment . Kemudian partisipan diberikan treatment. Setelah diberikan treatment, di akhir treatment partisipan diberikan tes (posttest) untuk mengetahui aspek tanggung jawab sosial dan keterikatan dengan asrama. Setelah itu, pengukuran kembali dilakukan dua minggu setelah pelatihan. Pada akhir pelatihan partisipan diberikan penjelasan mengenai eksperimen yang dilakukan dan diminta berefleksi mengenai tanggung jawab sosial yang telah dilaksanakan di asrama.

Treatment dilakukan dalam bentuk pelatihan. Dalam pelatihan ini terdapat tiga kegiatan, pertama adalah permainan public good games dimana aktivitas ini dilakukan untuk mengantar peserta mendapatkan insight pengambilan keputusan yang berdampak pada kepentingan bersama. Kegiatan pertama ini akan dilakukan beberapakali hingga peserta menemukan insight. Kegiatan yang kedua adalah permainan sirkus bola dan bermain peran. Kegiatan ini bertujuan agar peserta menyadari bahwa masalah yang dihadapi bersama perlu diselesaikan bersama. Kegiatan ketiga adalah analisis dan diskusi masalah yang bertujuan untuk menyadarkan peserta mengenai peran mereka dan apa yang seyogyanya mereka lakukan jika menghadapi masalah tersebut.

Setelah mengikuti program pelatihan, satu minggu kemudian Senior Resident diminta menyusun program aksi sosial kepada penghuni asrama X secara berkelompok. Syarat program aksi sosial yang disusun adalah yang dapat dijalankan dalam dua minggu, sederhana dan sesuai dengan dana yang telah disediakan. Terdapat empat kelompok dengan dua tema program aksi sosial. Dua kelompok dengan tema adaptasi dan dua kelompok lainnya dengan tema kebersihan lingkungan. Program aksi sosial yang disusun diberi umpan balik dan diberi pembimbingan oleh fasilitator. Setelah itu, Senior Resident diminta untuk menjalankan program aksi sosial tersebut dengan sasaran program adalah penghuni asrama $\mathrm{X}$.

\subsection{Pengumpulan Data}

Pengumpulan data dilakukan dengan pemberian skala pada penghuni asrama yang tinggal di lantai yang sama dengan Senior Resident. Skala yang diberikan meliputi kepuasan hidup berdampingan dengan Senior Resident $(\alpha=0,87)$ yang diadaptasi dari skala kepuasan Adriaanse (2007), skala place attachment $(\alpha=0,95)$ dari William \& Vaske (2003), dan skala sense of belonging $(\alpha=0,85)$ dari Hoffman, Richmond, Morrow, \& Salomone (2002). Pada penghuni asrama X, pengukuran dilakukan sebelum dan setelah menerima program aksi sosial dari Senior Resident. Pada Senior Resident diberikan skala place attachment $(\alpha=0,95)$ dari William \& Vaske (2003) dan skala tanggung jawab sosial $(\alpha=0,71)$ dari Berkowitz \& Lutterman (1968). Pengumpulan data dilakukan sebelum, setelah pelatihan dilaksanakan dan dua pekan setelah pelatihan.

Teknik analisis yang digunakan dalam penelitian ini menggunakan metode kuantitatif dan kualitatif. Metode kuantitatif yang digunakan adalah one way anova untuk kelompok partisipan Senior Resident. Melalui teknik ini peneliti akan menguji perbedaan dari skor sebelum dan sesudah intervensi. Pada partisipan penghuni asrama, teknik analisis yang digunakan adalah independent sample t-test, dimana membandingkan dua kelompok yaitu, kelompok yang tidak mendapatkan program aksi dari SR dan kelompok yang mendapatkan program aksi dari SR. Pada metode kualitatif peneliti melakukan wawancara setelah intervensi untuk mengetahui apakah ada perbedaan perilaku Senior Resident yang dirasakan oleh penghuni asrama setelah menerima pelatihan, dan apakah penghuni asrama menerima program aksi dari SR. Partisipan yang diwawancarai dipilih secara acak oleh peneliti. 


\section{HASIL DAN PEMBAHASAN}

Setelah dilakukan uji beda diperoleh hasil sebagai berikut:

Tabel 1. Nilai rata pretest, posttest dan pasca aksi Place of Attachment dan social responsibility Senior Resident asrama X

\begin{tabular}{ll}
\hline & Mean \\
\hline Pretest Place Attachment (PA1) & 57,12 \\
Posttest Place of Attachment (PA2) & 58,93 \\
pasca aksi Place of Attachment (PA3) & 60,27 \\
pretest social responsibility (SR1) & 39,94 \\
posttest social responsibility (SR2) & 40,00 \\
pasca aksi social oresponsibility (SR3) & 41,33 \\
\hline
\end{tabular}

Dari tabel diatas dapat dilihat bahwa ada peningkatan skor Place of Attachment yang diperoleh senior resident pada saat sebelum mendapat pelatihan, setelah mendapat pelatihan dan setelah melakukan aksi sosial untuk penghuni asrama di asrama. Peningkatan ini bernilai sekitar 1,14 - 2,71 poin, yaitu meningkat 2,71 poin pada saat setelah menerima pelatihan dan meningkat lagi 1,14 poin setelah melakukan aksi sosial untuk penghuni asrama. Pada skor Social responsibility, terdapat peningkatan skor yang diperoleh senior resident yaitu peningkatan sekitar 0,06 poin pada saat setelah mengikuti pelatihan dan meningkat lagi sebesar 1,14 poin pada saat setelah melakukan aksi sosial untuk penghuni asrama.

Tabel 2. Hasil perbandingan Place of Attachment dan social responsibility dari pretest, posttest dan pasca aksi

\begin{tabular}{llrr}
\hline & & $\begin{array}{r}\text { Selisih } \\
\text { Mean }\end{array}$ & Sig. \\
\hline Pair 1 & PA1 - PA2 & 2,71 &, 33 \\
Pair 2 & PA1 - PA3 & 3,40 &, 09 \\
Pair 3 & PA2 - PA3 & 1,14 &, 73 \\
Pair 4 & SR1 - SR2 & 0,06 &, 82 \\
Pair 5 & SR1 - SR3 & 1,13 &, 52 \\
Pair 6 & SR2 - SR3 & 1,14 &, 57 \\
\hline
\end{tabular}

Pada tabel 2, hasil menunjukkan nilai signifikansi place of attachment senior resident pada saat sebelum mendapat pelatihan (PA1), setelah mendapat pelatihan (PA2) dan setelah melakukan aksi sosial (PA3) lebih besar dari 0,05 (sig. > 0,05). Hal ini menunjukkan bahwa tidak ada perbedaan hasil yang signifikan skor place of attachment senior resident pada sebelum pelatihan, setelah pelatihan dan setelah melakukan aksi sosial. Hasil yang seruapa juga ditunjukkan pada variabel social responsibility dimana nilai signifikansi social responsibility senior resident pada saat sebelum mendapat pelatihan (SR1), setelah mendapat pelatihan (SR2) dan setelah melakukan aksi sosial (SR3) lebih besar dari 0,05 (sig. > 0,05). Hal ini menunjukkan bahwa tidak ada perbedaan hasil yang signifikan skor place social responsibility senior resident pada sebelum pelatihan, setelah pelatihan dan setelah melakukan aksi sosial. 
Tabel 3. Nilai rata penghuni asrama yang menerima aksi sosial dari Senior Resident dan yang tidak

\begin{tabular}{lr}
\hline & Mean \\
\hline Pretest Kepuasan & 34,61 \\
Posttest Kepuasan & 35,13 \\
Pretest Place Attachmet & 46,75 \\
Posttest Place Attachment & 49,52 \\
Pretest Sense of Belonging & 97,8 \\
Posttest Sense of Belonging & 105,87 \\
\hline
\end{tabular}

Selain pengukuran yang dilakukan pada Senior Resident, pengukuran juga dilakukan pada penghuni asrama sebelum mendapatkan program aksi sosial dari Senior Resident dan setelah mendapatkan program aksi sosial dari Senior Resident. Berdasarkan tabel 3, diperoleh hasil bahwa ada peningkatan skor kepuasan tinggal diasrama pada penghuni asrama setelah menerima program aksi sosial dari Senior Resident sebesar 0,52 poin. Pada skor Place Attachment diperoleh hasil peningkatan skor setelah mendapat program aksi sosial dari Senior Resident sebesar 2,39 poin. Dan pada variabel Sense of Belonging diperoleh peningkatan skor sebesar 9,71 poin setelah mendapatkan program aksi sosial dari Senior Resident.

Tabel 4. Perbandingan hasil penghuni asrama yang menerima aksi sosial dari Senior Resident dan yang tidak

\begin{tabular}{llll}
\hline & & Selisih & \\
& & Mean & sig. \\
\hline Pair 1 & Pre Kepuasan- Post Kepuasan & 0,52 &, 60 \\
Pair 2 & Pre PA - Post PA & 2,39 &, 47 \\
Pair 3 & Pre SoB - Post SoB & 9,71 &, 06 \\
\hline
\end{tabular}

Pada tabel 4, hasil menunjukkan nilai signifikansi kepuasan penghuni asrama pada saat sebelum dan setelah mendapat mendapat program aksi sosial dari Senior Resident lebih besar dari 0,05 (sig. > 0,05). Hal ini menunjukkan bahwa tidak ada perbedaan hasil yang signifikan kepuasan penghuni asrama pada saat sebelum dan setelah mendapat mendapat program aksi sosial dari Senior Resident. Pada varibel lain, hasil menunjukkan nilai signifikansi Place of Attachment penghuni asrama pada saat sebelum dan setelah mendapat mendapat program aksi sosial dari Senior Resident lebih besar dari 0,05 (sig. > 0,05). Hal ini menunjukkan bahwa tidak ada perbedaan hasil yang signifikan Place of Attachment penghuni asrama pada saat sebelum dan setelah mendapat mendapat program aksi sosial dari Senior Resident. Dan hasil menunjukkan nilai signifikansi Sense of Belonging penghuni asrama pada saat sebelum dan setelah mendapat mendapat program aksi sosial dari Senior Resident lebih besar dari 0,05 (sig. $>0,05)$. Hal ini menunjukkan bahwa tidak ada perbedaan hasil yang signifikan Sense of Belonging penghuni asrama pada saat sebelum dan setelah mendapat mendapat program aksi sosial dari Senior Resident.

Selain hasil kuantitatif, diperoleh juga data kualitatif yaitu Senior Resident yang telah mengikuti pelatihan merasa senang dengan adanya kegiatan ini karena lebih mengetahui tanggung jawab yang diemban selama menjabat di asrama X. Selain itu, Senior Resident merasa pelatihan ini memfasilitasi Senior Resident untuk membuat kegiatan yang tepat sasaran dan berpengaruh dalam mengatasi masalah adaptasi dan kebersihan lingkungan pada penghuni asrama $\mathrm{X}$. Pada penghuni asrama $\mathrm{X}$ ditemukan bahwa penghuni yang mendapat program aksi sosial merasa senang dengan adanya kegiatan ini karena membatu penghuni untuk saling mengenal tetangga asrama, yang sebelum ada program aksi sosial SR penghuni tidak mengenal. 
Penghuni juga merasa senang karena melalui program ini penghuni dapat mengetahui dengan jelas cara memilah sampah. Penghuni juga menjadi mengetahui mengetahui cara mengatasi sampah botol plastik yang telah digunakan agar tidak berserakan dan memudahkan pendaur ulang dalam memilah.

\subsection{Diskusi}

Berdasarkan hasil yang diperoleh diatas ditemukan bahwa tidak ada perbedaan yang signifikan Place of Attachment dan Social Responsibility sebelum dan setelah mengikuti pelatihan pada Senior Resident. Selain itu, tidak ada perbedaan yang signifikan Place of Attachment dan Social Responsibility setelah menjalankan program aksi sosial, meskipun terdapat peningkatan skor dari pengukuran pertama hingga pengukuran ketiga. Hal serupa juga terjadi pada penghuni asrama, tidak ada perbedaan yang signifikan pada kepuasan tinggal di asrama, place of attachment, dan sense of belonging pada sebelum dan setelah mendapatkan program aksi sosial dari Senior Resident.

Hasil yang diperoleh diatas bisa saja dipengeruhi oleh beberapa faktor. Menurut Haywood (1992) pelatihan yang efektif dipengaruhi oleh adanya dukungan organisasi atas perubahan; komitmen dan kepercayaan yang kuat dalam pendidikan, pelatihan dan pengembangan individu; pelatihan dan pengembangan yang berhubungan dengan strategi dan tujuan yang ingin dicapai; formulasi dan implementasi dari strategi; peserta bukan hanya menerima pengetahuan dan kemampuan tapi juga mendemonstrasikan kompetensi, termasuk menemukan keinginan pelanggan; pelatihan diawali dengan menyusun tujuan dan hasil yang diharapkan; adanya spesifikasi dalam pelatihan; serta adanya evaluasi menyeluruh atas efektifitas pelatihan.

Dalam pelatihan tanggung jawab sosial yang dilakukan oleh peneliti, telah memenuhi syarat agar pelatihan berlangsung efektif dan menghasilkan peningkatan signifikan pada aspekaspek yang diukur pada peserta pelatihan dalam hal ini Senior Residnt dan penghuni asrama. Hal ini, ditunjukkan dengan adanya peningkatan skor dari waktu ke waktu walaupun tidak signifikan. Sehingga diduga bahwa penyebab tidak adanya perbedaan atau peningkatan yang signifikan dari skor yang diperoleh adalah karena pelatihan yang hanya dilakukan pada satu waktu. Hal ini menjadikan sedikitnya kesempatan dan frekuensi peserta terpapar dengan pengetahuan dan pengalaman mengenai tanggung jawab sosial yang diberikan oleh fasilittator. Pernyataan ini didukung oleh pendapat Johnson \& Johnson (2013) yang mengatakan bahwa pelatian dan penyampaian informasi akan efektif jika informasi dan pengetahuan yang ingin disampaikan diberikan secara berkala dan terus menerus. Sehingga pelatihan akan efektif dan berhasil meningkatkan tanggung jawab sosial Senior Resident terhadap asrama X dan penghuni asrama lain dapat merasakan dampaknya.

Namun, secara kualitatif dapat ditemukan perbedaan pada saat sebelum dan setelah intervensi. Pada setelah intervensi Senior Resident menjadi lebih paham tanggung jawabnya secara spesifik. Sehingga Senior Resident menjadi tahu apa yang perlu dilakukan untuk mengatasi msalah adaptasi dan kebersihan lingkungan di asrama. Sedangkan pada penghuni asrama, setelah mengikuti program aksi sosial dari SR, penghuni asrama menjadi saling kenal tetangga asrama mereka. Selain itu, penghuni juga semakin kenal dengan Senior Resident dan merasa dekat dengan mereka.

\section{KESIMPULAN}

Dari hasil dan pembahasan diatas dapat disimpulkan bahwa tidak ada perbedaan yang signifikan Place of Attachment dan Social responsibility Senior Resident di asrama X sebelum dan setelah pelatihan tanggung jawab sosial diberikan sebanyak satu kali pelatihan. Selain itu, tidak ada perbedaan yang signifikan kepuasan menetap di asrama, Place of attachment dan Sense of Belonging terhadap asrama pada penghuni asrama sebelum dan setelah penghuni 
asrama menerima program aksi sosial dari Senior Resident. Hal ini disebabkan karena pemberian pelatihan kepada Senior Resident hanya sekali.

\section{SARAN}

Oleh karena itu pada penelitian selanjutnya, disarakan untuk melakukan pelatihan lebih lama dan beberapa kali agar pengetahuan dan pengalaman mengenai tanggung jawab sosial dapat efektif dan meningkatka aspek-aspek psikologis Senir Resident dan Penghuni Asrama di Asrama X.

\section{DAFTAR PUSTAKA}

[1] Adriaanse, C. C. M. "Measuring residential satisfaction: a residential environmental satisfaction scale (RESS)". Journal of housing and the built environment, 2007, 22(3), 287.

[2] Austin, D. Mark, L. Allen Furr, and Michael Spine. "The effects of neighborhood conditions on perceptions of safety." Journal of criminal justice 30.5 (2002): 417-427.

[3] Bell, Greene, and C. Greene. "Fisher, \& Baum (2001). Environmental Psychology." (2011).

[4] Berkowitz, L., \& Lutterman, K. G. "The traditional socially responsible personality". Public Opinion Quarterly, 1968, 32(2), 169-185.

[5] Botti, S., \& McGill, A. L. "When choosing is not deciding: The effect of perceived responsibility on satisfaction". Journal of Consumer Research, 2006, 33(2), 211-219.

[6] Burhanuddin, S., H. "Etika Individual:. Jakarta: Rineka Cipta. 2000.

[7] Fischer, J. M., \& Ravizza, M. "Responsibility and control: A theory of moral responsibility”. Cambridge university press. 2000.

[8] Haywood, K. M. "Effective training: Toward a strategic approach". Cornell Hotel and Restaurant Administration Quarterly, 1992, 33(6), 43-52.

[9] Heidari, A. A., \& Nekooeimehr, F. "An investigation of the relationship between sense of place and place attachment among dormitory students". Iran University of Science \& Technology, 2013, 23(2), 121-131.

[10] Hoffman, M., et al. "Investigating "sense of belonging" in first-year college students". Journal of College Student Retention: Research, Theory \& Practice, 2002, 4(3), 227-256.

[11] Johnson, D. W., \& Johnson, F. P. “ Joining together: Group theory and group skills (11" Ed.). 2013.

[12] Junot, A., Paquet, Y., \& Fenouillet, F. "Place attachment influence on human well-being and general pro-environmental behaviors". Journal of Theoretical Social Psychology, 2018, 2(2), 49-57. 
[13] Kaplan, Stephen, and Rachel Kaplan. "Health, supportive environments, and the reasonable person model." American Journal of Public Health 93.9 (2003): 1484-1489.

[14] Kutty, Nandinee. "Determinants of structural adequacy of dwellings." Journal of housing research 10.1 (1999): 27-43.

[15] Morris, Earl W., Sue R. Crull, and Mary Winter. "Housing norms, housing satisfaction and the propensity to move." Journal of Marriage and the Family (1976): 309-320.

[16] Mowen, John C., and Michael Minor. "Consumer Behavior. 6-th ed." Jersey: Prentice Hall (2008).

[17] Raphael, T. E., \& Pearson, P. D. "Increasing students' awareness of sources of information for answering questions". American Educational Research Journal, 1985, $22(2), 217-235$.

[18] Scannell, L., \& Gifford, R. "Place attachment enhances psychological need satisfaction". Environment and Behavior, 2017, 49(4), 359-389.

[19] Secchi, D., \& Bui, H. T. "Group effects on individual attitudes toward social responsibility". Journal of Business Ethics, 2018, 149(3), 725-746.

[20] Shahyad, S., et al. "The relation of attachment and perceived social support with life satisfaction: structural equation model”. Procedia-Social and Behavioral Sciences, 2011, 15, 952-956.

[21] Singh, A. "Investigating the sense of belonging of international students through a predictive model". 2018.

[22] Sugihara, S., \& Evans, G. W. "Place attachment and social support at continuing care retirement communities". Environment and Behavior, 2000, 32(3), 400-409.

[23] Vaske, J. J., \& Kobrin, K. C. "Place attachment and environmentally responsible behavior". The Journal of Environmental Education, 2001, 32(4), 16-21.

[24] Weijs-Perrée, M., et al. "Social networks, social satisfaction and place attachment in the neighborhood". Region, 2017, 4(3), 133-151.

[25] Williams, D. R., \& Vaske, J. J. "The measurement of place attachment: Validity and generalizability of a psychometric approach". Forest science,2003, 49(6), 830-840. 